\title{
An experimental investigation of contact characteristics of crown gear coupling with angular misalignment
}

\author{
Yabin GUAN*, Jigang CHEN*, Hao CHEN*, Shengyang HU** and Xuan LIU** \\ *School of Mechanical Engineering, Yanshan University, \\ No. 438 West Hebei Avenue, Qinhuangdao 066004, China \\ E-mail: 24000082@qq.com \\ **School of Mechanical Engineering, Northwestern Polytechnical University, \\ No. 127 West Youyi Road, Xi'an 710072, China
}

Received: 15 June 2021; Revised: 24 July 2021; Accepted: 19 August 2021

\begin{abstract}
Crown gear couplings are commonly applied to transfer rotary motion and torsion from one rotating component to another under a certain misalignment angle. While computational models for contact analysis have recently been proposed, there is no validated contact analysis model of crown gear coupling with angular misalignment due to lack of experimental data. Accordingly, this study proposes to establish an extensive experimental database on contact characteristics of the conventional and novel crown gear couplings with different misalignment angles. A dedicated test rig, which can adjust misalignment angle, is designed and set up. A test matrix covering various misalignment angle conditions is executed in order to form a meshing contact database for crown gear coupling. The experimental data illustrates the variety of contact positions on the hub tooth surface caused by rotational position and misalignment angle. Simulation results obtained by loaded tooth contact analysis are compared to the experimental results for the conventional and novel crown gear couplings with different misalignment angles. The results show that the simulation model used to calculate contact analysis is effective, and the meshing performance of the innovative hub tooth profile is better than that of the conventional one.
\end{abstract}

Keywords : Crown gear coupling, Meshing test, Angular misalignment, Loaded tooth contact analysis, Innovative hub tooth profile

\section{Introduction}

A crown gear coupling mainly consists of a hub that is an external gear, and a sleeve that is an internal spur gear. The hub has longitude crowning and tip sphere teeth, which can compensate angular misalignment between the hub and the sleeve. Moreover, the number of the hub teeth is the same as that of the sleeve teeth. Because of the advantages of compact structure, high loading capacity and wide speed range, crown gear couplings are widely used in high speed railway (Shinoda and Li, 2020), large ships (Fan et al., 2020), precision rolling machinery (Peng et al., 2018) and other equipment serving in complex working condition.

Angular misalignment between the hub and the sleeve of the crown gear coupling is always recognized as harmful for its performance because excessive angular misalignment can cause a significant load concentration towards the tooth end of the hub or sleeve, and accelerates tooth surface wear of the crown gear coupling (Locke et al., 2013). As a consequence, it is important to study contact analysis for the crown gear coupling when the hub is misaligned with the sleeve. Several theoretical studies have been carried out for this. Calculating the clearance between adjacent teeth by dividing tooth surface of the hub into several nodes, Alfares (2006) studied the influence of various coupling geometrical parameters on the minimum clearance distribution along the circumferential in the presence of angular misalignment. The results show that angular misalignment is the main factor for determining the clearance distribution and optimum crowning can help improve the clearance distribution. Using the method to calculate clearance proposed by Alfares, Zhao et al. (2017) compared the contact characteristics of four types of crowning curves, and discovered 
that the minimum clearance distribution of the crown gear coupling with three-segment circular arcs is more gentle than the others. To obtain a larger contact area and a smaller clearance related to the backlash-hit noise between teeth, Hakozaki and Shimachi (2004) adjusted the radius of curvature along the hub tooth width direction to modify the contact area of the crown gear coupling with angular misalignment. Based on the theories of differential geometry and gear mesh, Guan et al. (2018) accomplished geometrical mathematical models, proposed a tooth contact analysis technique, and discussed the effects of misalignment angle and crowning on the minimum circumferential clearance, and contact path for this special device. Based on the proposed tooth contact analysis technique above, Guan et al. (2019a) compared three geometric models for the crown gear coupling on tooth contact analysis, and found that when the coupling is misaligned, a serious load concentration occurs at the hub or sleeve tooth tip edge. Guo et al. (2013, 2015) developed a new analytic model to calculate the number of teeth in contact, load sharing, stiffness, stress, deformation, and safety factors for a given torque and angular misalignment which fully considered contact, bending and shear deformations of the teeth. And, load sharing among teeth agrees well with that obtained by high fidelity finite element method. Keum (2003) analyzed the effect of misalignment angle upon contact pressure distribution on tooth surface and load sharing among teeth by finite element method. From the analysis results, it can be seen that with the increase of misalignment angle, contact position moves farther away from the middle to the end along the hub tooth width direction. To avoid the occurrence of the edge contact when misaligned, a novel crown gear coupling composed of a hub with profile crowning, longitude crowning, and tip sphere teeth, and a sleeve with straight internal teeth was presented by Guan et al. (2019b).

On the experimental side, there is limited measured data on meshing contact of the crown gear coupling with angular misalignment which leaves the models above essentially without validation. Wang and Shen (2006) measured the axial displacement, radial displacement, temperature and strain of the crown gear coupling on the traction gear loading test-bed. The test results show that temperature rises, vibration and noise increase, and both tooth ends are seriously worn in a short time when misalignment angle reaches the maximum. Ohshima et al. (2012) presented a new hub tooth surface interpolated from many section parabolic profiles to bring good tooth contact for gear couplings, and verified by the meshing test of the crown gear coupling. However, the test principle and device were not given. He (2013) carried out the loading test of crown gear coupling considering the actual working condition of concrete truck, and discovered that edge contact occurs between the hub tooth tip edge contact with the sleeve tooth root flank and the sleeve tooth tip edge contact with the hub tooth root flank. Guo et al. (2016) predicted the induced loads affected by misalignment, torque and friction by the proposed new analytic model for crown gear couplings, and carried out the experimental verification at the NWTC's 5-MW dynamometer. These experimental studies were tailored to address operating characteristics concerns and many test devices don't have the function to measure the misalignment angle. As such, they offered little towards validation of contact analysis models considering angular misalignment.

Therefore, this study designs and sets up a dedicated test rig which can adjust misalignment angle of crown gear coupling to measure contact positions. According to the conventional and innovate tooth modification theories for the hub, the specimens with the same structure for test are designed and processed, and the machining accuracy of tooth surface are tested. Simulations of the tested conventional and novel crown gear couplings will be performed by loaded tooth contact analysis (Guan et al., 2019b) to provide a direct comparison to the experimental results under the condition of misalignment angle $0^{\circ}, 0.4^{\circ}, 0.6^{\circ}$ and $0.8^{\circ}$ to validate the accuracy of the simulation model. Moreover, experimental results obtained by using the convention and novel crown gear couplings with the maximum misalignment angle are also compared to present the superiority of the innovative hub tooth profile.

\section{Loaded tooth contact analysis for crown gear coupling}

There are only two or three pairs of teeth engaging at the same time for general gear transmission, such as cylindrical gear transmission. Therefore, three- or five-tooth finite element model is often used to conduct loaded tooth contact analysis for general gear transmission. However, the motion law of crown gear coupling is quite different from that of general gear transmission (Guan et al., 2018). Under the condition of angular misalignment, all the teeth of crown gear coupling can participate into contact at the same time, and the contact condition of the engaging tooth is different from each other. Therefore, it is necessary to establish the full-tooth finite element model to study the contact condition of crown gear coupling with misalignment angle.

Coordinate systems for loaded tooth contact analysis of crown gear coupling with misalignment angle are shown in 
Fig. 1(a), where coordinate systems $S_{h}\left(O_{h}, x_{h}, y_{h}, z_{h}\right), S s\left(O_{s}, x_{s}, y_{s}, z_{s}\right)$, and $S_{f}\left(O_{f}, x_{f}, y_{f}, z_{f}\right)$ are rigidly connected to the hub, sleeve, and the fixed frame, respectively. $S_{f 1}\left(O_{f 1}, x_{f 1}, y_{f 1}, z_{f 1}\right)$ and $S_{\theta}\left(O_{\theta}, x_{\theta}, y_{\theta}, z_{\theta}\right)$ are the auxiliary coordinate systems for simulating angular misalignment error between the hub and sleeve. Parameters $\varphi_{h}, \varphi_{s}$ are rotation angles of the hub and sleeve, and $\theta$ is the misalignment angle between the hub and sleeve in Fig.1 (a). Besides, $\Delta E$ is just used to express the position relationship of the hub and sleeve conveniently, and the value of $\Delta E$ is 0 .

After establishing the finite element mesh models of the hub and sleeve in the respective coordinate systems $S_{h}\left(O_{h}, x_{h}, y_{h}, z_{h}\right)$ and $S s\left(O_{s}, x_{s}, y_{s}, z_{s}\right)$, high-precision assembly between the hub and sleeve must be carried out in the fixed coordinate system $S_{f}\left(O_{f}, x_{f}, y_{f}, z_{f}\right)$ by using the coordinate transformation according to the position relationship shown in the coordinate system in Fig. 1(a). And, the assembled finite element mesh model and boundary conditions in ANSYS as it is illustrated in Fig. 1(b). The nodes on rim surface (red area) of the sleeve are fully constrained. Moreover, the nodes on inner part (yellow area) of the hub constitute a rigid surface that is rigidly connected to a reference node defined at point $O_{f}$. The reference node is constrained except the rotation about the rotating axis, and a load is applied directly at the reference node in the hub model.

(a)

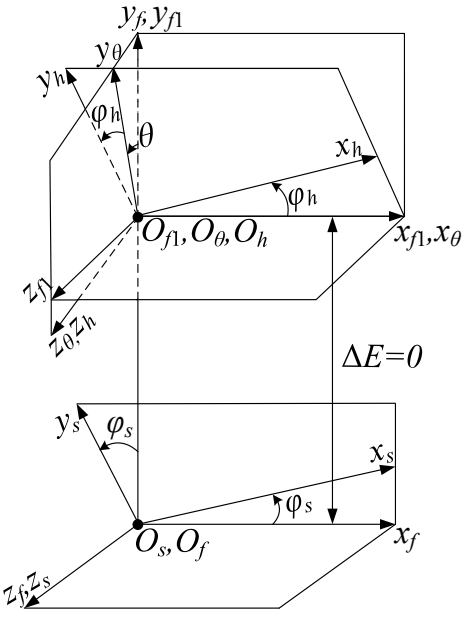

(b)

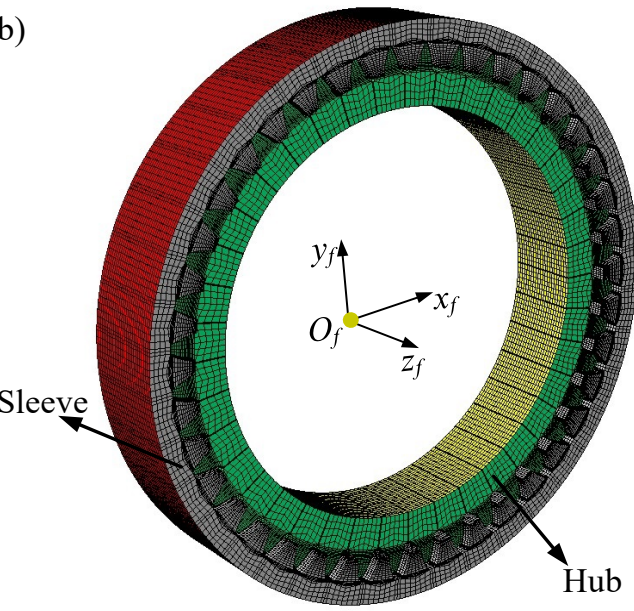

Fig. 1 Loaded tooth contact analysis for crown gear coupling: (a) coordinate systems used to define the position relationship between the hub and sleeve, and (b) assembled full-tooth finite element mesh model and boundary conditions in ANSYS.

\section{Designing of test crown gear couplings}

A conventional crown gear coupling mainly consists of a hub with longitude crowning and tip sphere teeth and a sleeve with straight internal teeth. To prevent edge contact, profile modification is added to the hub tooth surface of the conventional crown gear coupling. And, the hub with profile crowning, lead crowning, and tip sphere teeth, and the sleeve with straight internal teeth form a novel crown gear coupling. Comparison of the hub tooth surfaces of the conventional and novel crown gear couplings is shown in Fig. 2.

(a)

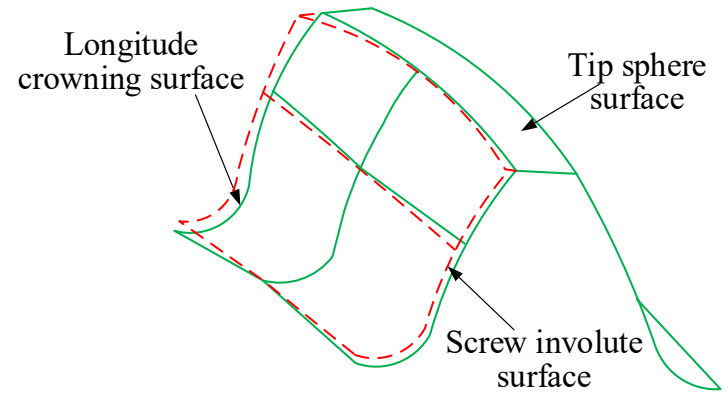

(b)

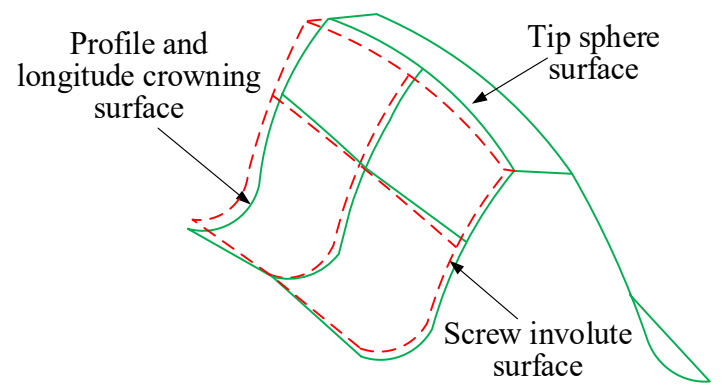

Fig. 2 Geometric comparison of the conventional and novel crown gear couplings' hub tooth surfaces: (a) conventional crown gear coupling, and (b) novel crown gear coupling.

In order to compare and verify the meshing performance of the conventional and novel gear couplings, the same basic parameters of them are taken. Table 1 lists the basic parameters of test crown gear couplings considered in this study. In addition to the parameters listed in the table, it is also specified that parameters $a_{c}$ and $l_{a}$ which are the novel 
crown gear coupling's parabolic rack cutter surface parameters are -0.0025 and 0 , respectively. The detailed description about parameters $a_{c}$ and $l_{a}$ can be found in the reference (Guan et al., 2019b).

Table 1 Basic parameters of test crown gear couplings.

\begin{tabular}{c|c|c}
\hline \hline Parameters & Hub & Sleeve \\
\hline Number of teeth $z$ & 40 & 40 \\
\hline Module $m[\mathrm{~mm}]$ & 3 & 3 \\
\hline Tooth face width $b[\mathrm{~mm}]$ & 18 & 23 \\
\hline Normal pressure angle $\alpha\left[^{\circ}\right]$ & 20 & 20 \\
\hline Addendum of tooth $h_{a}[\mathrm{~mm}]$ & 3 & 3 \\
\hline Dedendum of tooth $h_{f}[\mathrm{~mm}]$ & 3.75 & 3 \\
\hline Displacement circle radius $R_{d s}[\mathrm{~mm}]$ & 100 & - \\
\hline Tool tip radius $r_{t}[\mathrm{~mm}]$ & 1.14 & 0.45 \\
\hline Maximum value of misalignment angle $\theta_{\max }\left[{ }^{\circ}\right]$ & 0.8 & - \\
\hline
\end{tabular}

Profile modification curve of the hub tooth surface is plotted by a series of discrete points in the middle of the tooth width along the meshing line direction and the corresponding modification amount. The corresponding profile modification amount is determined by the distance along the norm direction between the modified profile curve and standard involute curve. Moreover, lead modification curve of the hub tooth surface is plotted by a series of discrete points in the middle of the tooth height along the tooth width direction and the corresponding lead modification amount. The corresponding lead modification amount is determined by the distance at the discrete point along the norm direction between the modified lead curve and straight line. Because no profile modification is added to the conventional crown gear coupling's hub tooth surface, there is no need to present profile modification curve for the conventional crown gear coupling's hub tooth surface. Lead modification curve of the conventional crown gear coupling's hub tooth surface is shown in Fig. 3. It represents lead modification curve with different modification amounts.

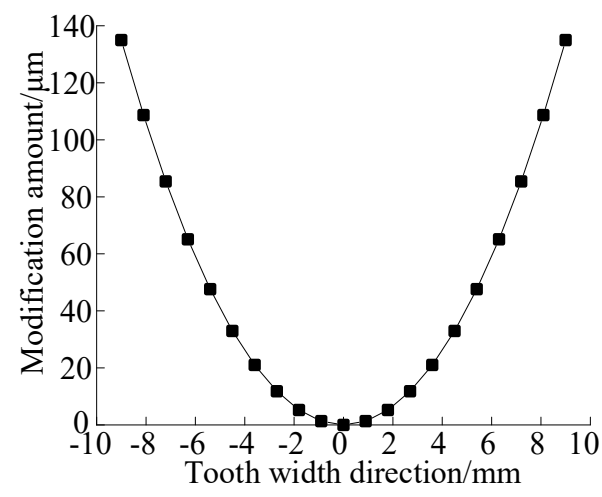

Fig. 3 Lead modification curve of the conventional crown gear coupling's hub tooth surface.

Profile modification curve and lead modification curve of the novel crown gear coupling's hub tooth surface are shown in Fig. 4(a) and Fig. 4(b). It represents modification curves with different modification amounts.

Based on the proposed tooth contact analysis (Guan et al., 2018) for crown gear coupling, the minimum circumferential simulation backlash of the conventional and novel crown gear couplings can be obtained. Assuming that the initial position of the single pair of teeth is in the pure pivoted area, where the initial rotation angle is specified as $0^{\circ}$. The single pair of teeth are rotated in a counter clockwise direction with a step of $15^{\circ}$ to calculate the minimum circumferential clearance of the conventional and novel crown gear couplings at any rotation angle. And, the minimum circumferential clearance is the minimum circumferential distance along the pitch circle between the adjacent tooth surfaces of the single pair of teeth above. Fig. 5(a) and Fig. 5(b) show the minimum circumferential clearance between adjacent tooth surfaces at different rotation angles of the conventional and novel crown gear couplings with the maximum misalignment angle of $0.8^{\circ}$. It can be seen that the minimum circumferential clearance of the two types of 
crown gear coupling reaches the minimum value near the pure turnover area, and the minimum values are $-73 \mu \mathrm{m}$ and $-43 \mu \mathrm{m}$, respectively. In order to make the hub and the sleeve mesh normally at any meshing position, it is necessary to make the minimum simulation circumferential backlash greater than two times of the absolute value of the minimum circumferential clearance. Therefore, the values of the minimum circumferential simulation backlash for the conventional and novel crown gear couplings are $146 \mu \mathrm{m}$ and $86 \mu \mathrm{m}$.

(a) $\quad 30$

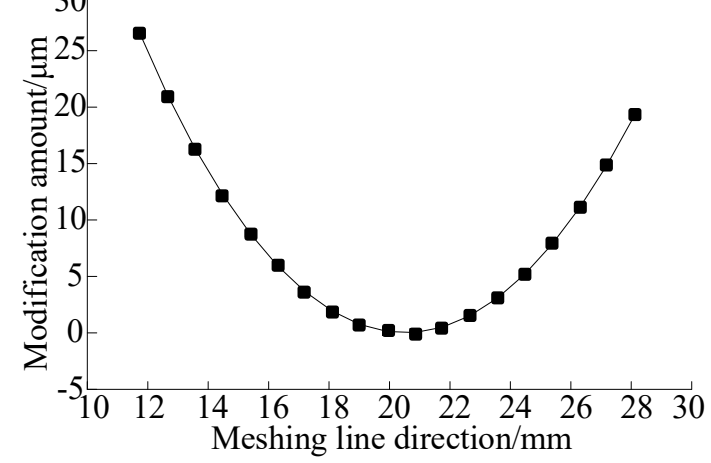

(b)

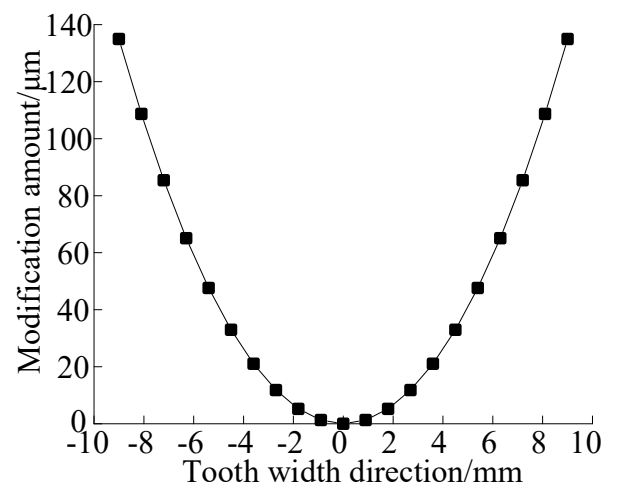

Fig. 4 Modification curves of the novel crown gear coupling's hub tooth surface: (a) profile modification curve, and (b) lead modification curve.

(a)

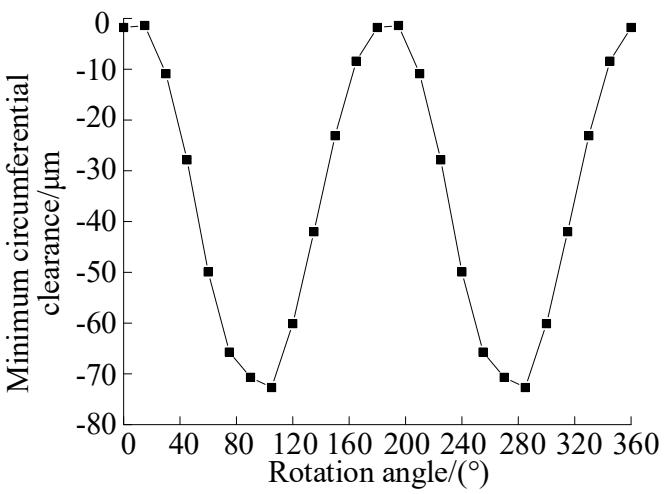

(b)

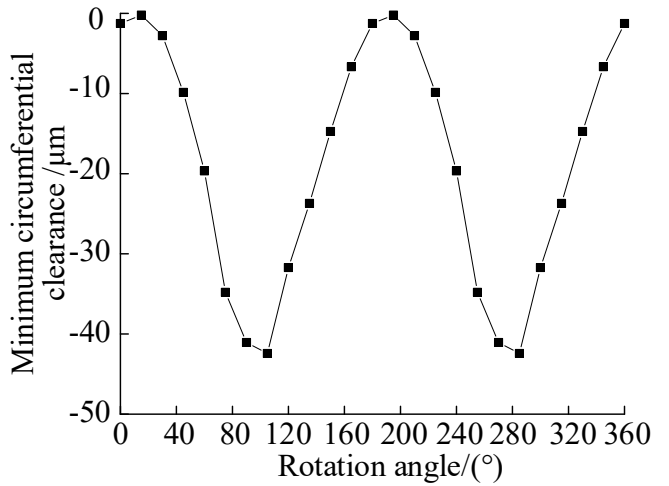

Fig. 5 Minimum circumferential clearance between adjacent tooth surfaces varies with rotation angle without considering backlash under the condition of the maximum misalignment angle $0.8^{\circ}$ : (a) conventional crown gear coupling, and (b) novel crown gear coupling.

In addition to ensuring the minimum circumferential simulation backlash $J_{t m i n}$ required for normal meshing at the intersection angle, the compensation for manufacturing error $\delta_{n 1}$ should also be considered when machining the test crown gear coupling. And, the calculation formula of $\delta_{n 1}$ can be obtained as follows:

$$
\delta_{n 1}=\left[\left(F_{p 1}+F_{p 2}\right) \cos \alpha+\left(f_{f 1}+f_{f 2}\right)+\left(F_{g}+F_{\beta 2}\right)\right],
$$

where, $F_{p 1}$ and $F_{p 2}$ are the cumulative pitch deviations of the hub and the sleeve respectively; $f_{f 1}$ and $f_{f 2}$ are the profile form deviations of the hub and the sleeve respectively; $F_{g}$ is the symmetry deviation of the hub tooth surface; $F_{\beta 2}$ is the total helix deviation of the sleeve.

According to the grade of machining accuracy, it can be easily found from GB10095-88 that $F_{p 1}, F_{p 2}, f_{f 1}, f_{f 2}, F_{g}$ and $F_{\beta 2}$ are $28 \mu \mathrm{m}, 45 \mu \mathrm{m}, 6 \mu \mathrm{m}, 8 \mu \mathrm{m}, 10 \mu \mathrm{m}$ and $9 \mu \mathrm{m}$, respectively. The calculated $\delta_{n 1}$ is $102 \mu \mathrm{m}$ by substituted the deviation values above into Eq. (1).

And, the relationship between the minimum circumferential simulation backlash $J_{\text {tmin }}$ and the minimum normal simulation backlash $J_{n \min }$ can be represented as follows:

$$
J_{\text {nmin }}=J_{\text {tmin }} \cos \alpha,
$$

where $\alpha$ is the pressure angle. 
The normal backlash of the test crown gear coupling for machining can be expressed as follows:

$$
J_{n}=J_{n \min }+\delta_{n 1} .
$$

The normal backlash of the conventional crown gear coupling and the novle crown gear coupling are $240 \mu \mathrm{m}$ and $183 \mu \mathrm{m}$, which can be derived by combining Eqs. (2) and (3).

\section{Manufacturing and testing of test crown gear coupling}

\subsection{Hub}

The manufacturing of the conventional and novel crown gear couplings' hub is carried out on YK7332A CNC gear grinding machine developed by Qinchuan Machine Tool Group, as shown in Fig. 6(a). The CAM system of YK7332A machine tool has a fixed profile modification module, which only needs to input the basic parameters such as the number of teeth, modulus, pressure angle, tooth profile modification and tooth direction modification parameters to realize the tooth profile and tooth direction modification, and the tooth surface grinding of grade 5 or higher accuracy can be achieved. In addition, the working principle of YK7332A is form grinding. The profile of the form grinding wheel is modified via on an on-board wheel dressing system utilizing a diamond dressing wheel, as shown in Fig. 6(b). Furthermore, the form grinding wheel can be used to facilitate grinding of the workpiece tooth forms precisely, as shown in Fig. 6(c). And, the hub generated by the form grinding wheel is also shown in Fig. 6(d).

(a)

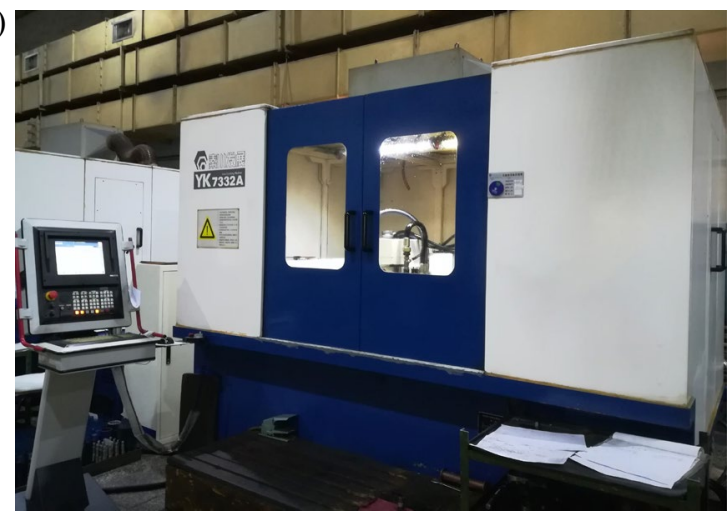

(c)

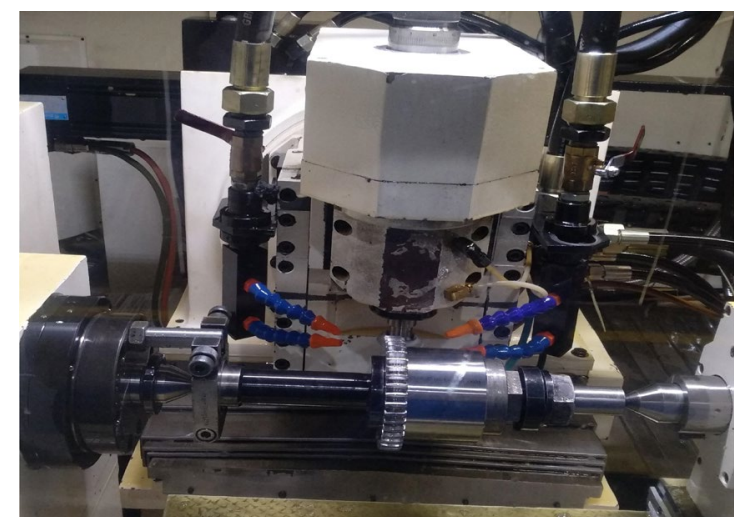

(b)

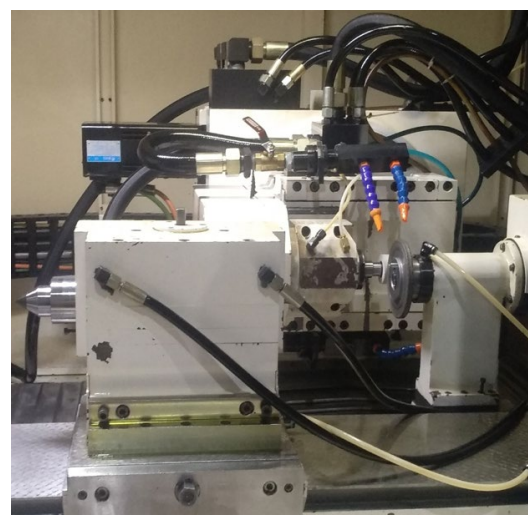

(d)

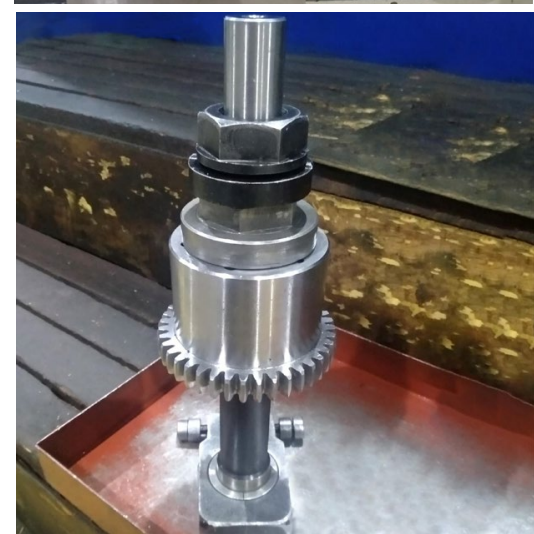

Fig. 6 Grinding equipment and process of the hub tooth surface: (a) YK7332A CNC gear grinding machine, (b) wheel dressing system, (c) grinding hub tooth surface, and (d) finished hub.

After manufacturing, the testing of tooth surface of the conventional crown gear coupling's hub and the novel crown gear coupling's hub is carried out in 3906T Gear Measuring Center. And, comparisons of simulation design and actual processing of modification curves of the conventional crown gear coupling's hub and the novel crown gear coupling's hub are shown in Fig. 7 and Fig. 8 respectively. It can be seen from these two figures that the actual machining results of the tooth surface modification of the conventional crown gear coupling's hub and the novel crown gear coupling's hub are basically consistent with the simulation design results. 
(a)

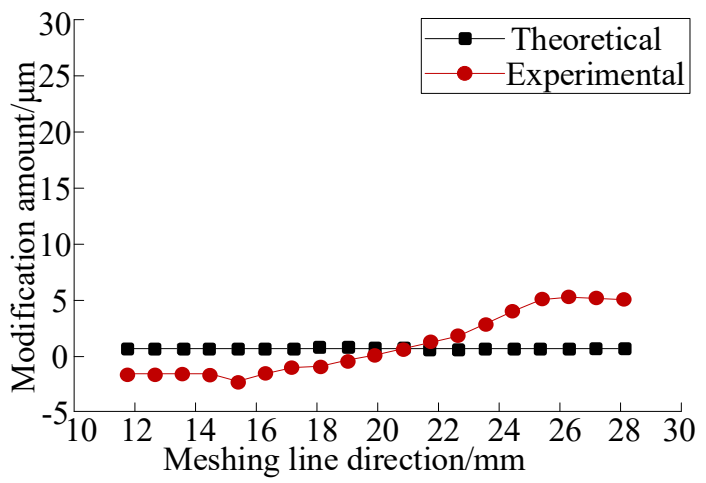

(b)

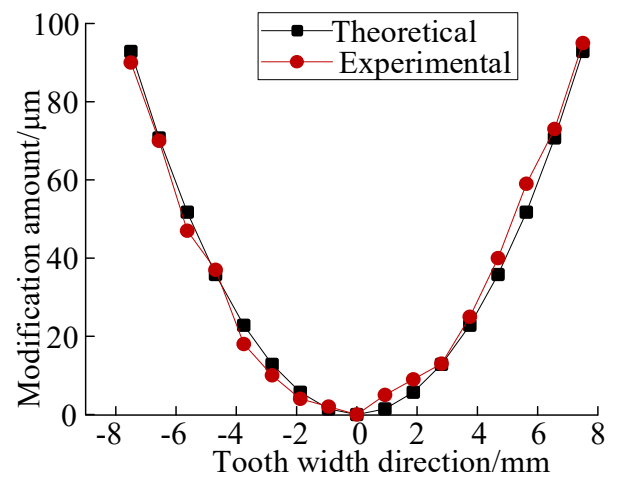

Fig. 7 Comparison of simulation and experimental results of the conventional crown gear coupling's hub: (a) profile modification curve, and (b) lead modification curve.

(a) $\quad 30$

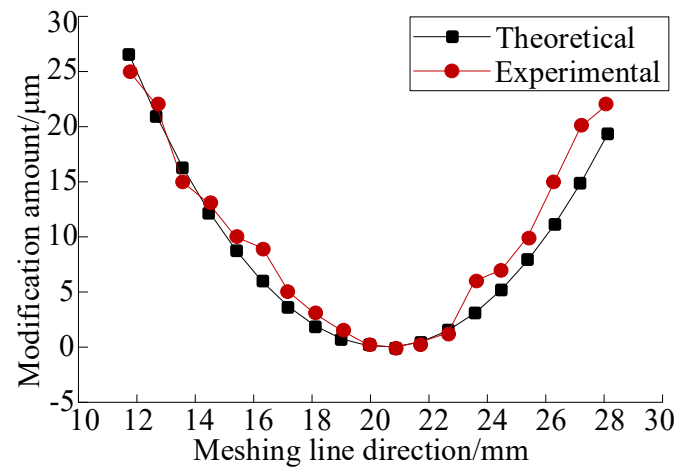

(b)

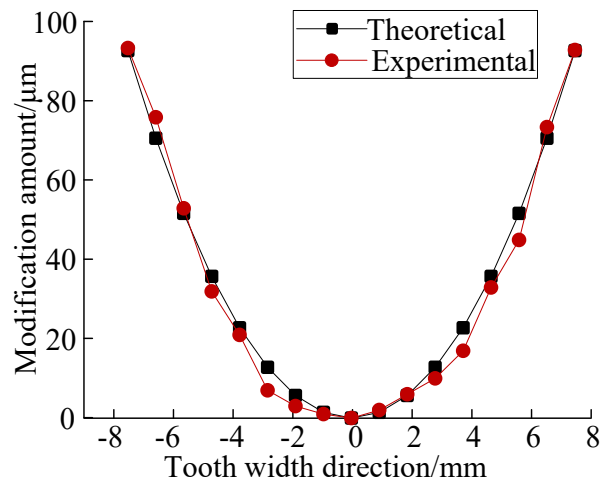

Fig. 8 Comparison of simulation and experimental results of the novel crown gear coupling's hub: (a) profile modification curve, and (b) lead modification curve.

\subsection{Sleeve}

For the machining of the sleeve, due to the limitation of gear grinding conditions, YK5150A CNC gear shaper with machining accuracy up to grade 6 is adopted in this test. The sleeve manufactured by YK5150A is shown in Fig. 9. And, the accuracy of the sleeve's tooth surface is tested on the GMC650 Gear Measuring Center. The results show that the accuracy of the tooth surface reaches grade 6 .

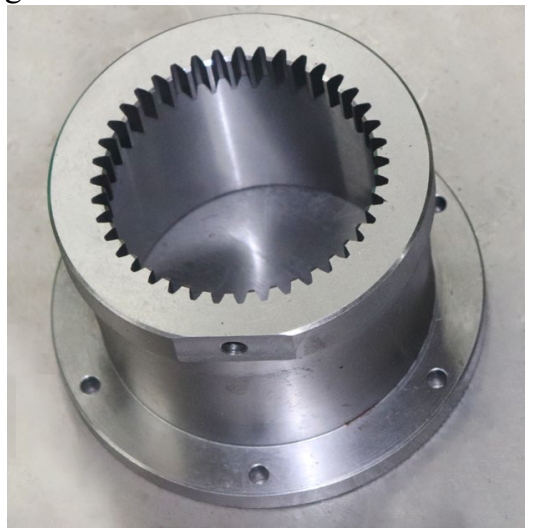

Fig. 9 Sleeve machined by YK5150A CNC gear shaper.

\section{Experimental Setup}

A dedicated experimental setup that allows a crown gear coupling to be tested under various misalignment angle has been designed and manufactured. Fig. 10(a) and Fig. 10(b) show the assembly front view and top view of the test with key components labeled, and Fig. 10(c) shows the experimental setup. 
(a)

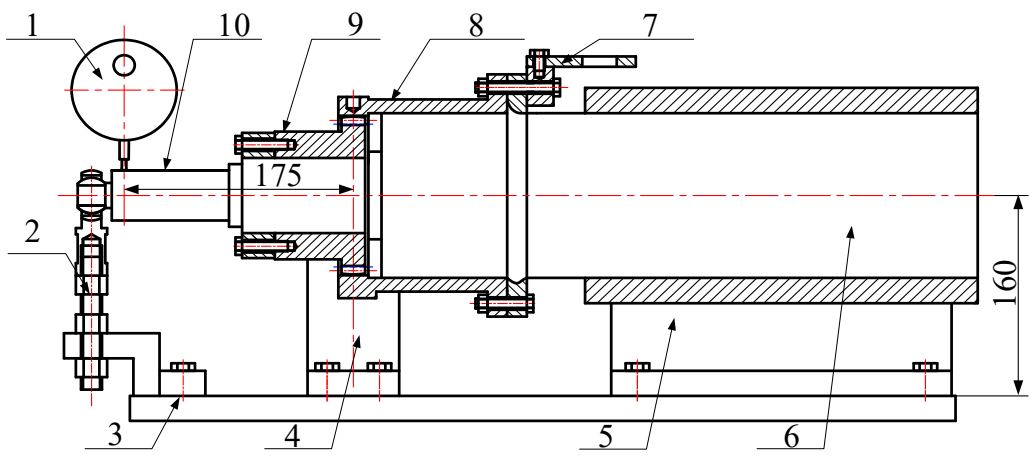

(b)

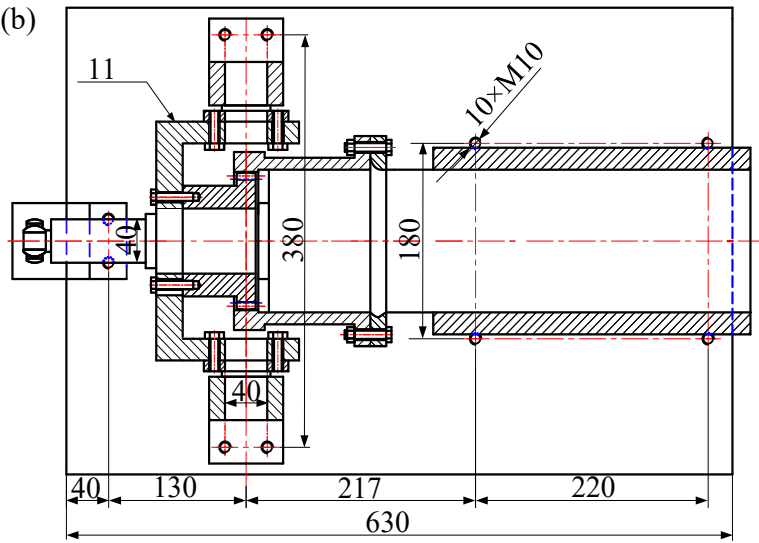

(c)

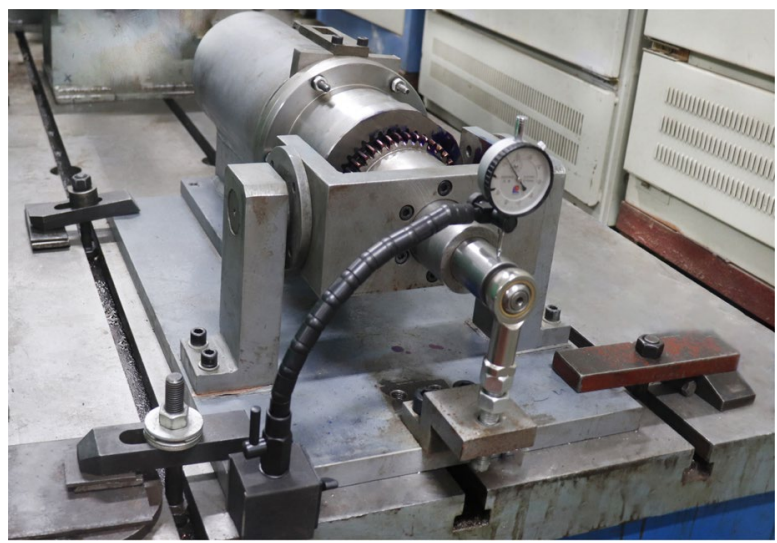

1-Dial indicator; 2-Displacement controlled screw; 3-Mounting base; 4-Left and right brackets; 5-Sleeve bracket 6-Sleeve shaft; 7-Loading handle; 8-Sleeve; 9-Hub; 10-Hub shaft; 11-Swing bracket

Fig. 10 Views of the test assembly and experimental setup: (a) front view, (b) top view, and (c) experimental setup.

The key step of the meshing test for crown gear coupling with adjustable misalignment angle is how to adjust the position of swing bracket to make the hub and sleeve aligned. Fig.11 shows that how to achieve the initial axial alignment position. And, the initial axial alignment position can be obtained when the adjusted hub shaft can rotate and move freely in the sleeve shaft hole.

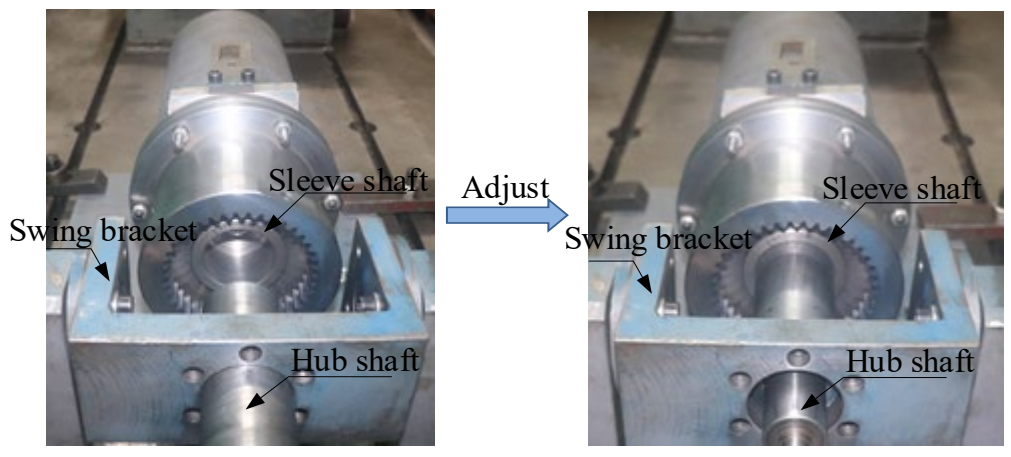

Fig. 11 Adjustment of initial aligned position for crown gear coupling.

\section{Results and discussion}

The conventional and novel crown gear couplings are respectively installed on the above designed meshing test bench. And the meshing test is carried out by applying the blue marking liquid to the hub tooth surface after adjusting the axial alignment of the hub and sleeve. Moreover, the dial indicator scale for axial alignment is also set to $0 \mathrm{~mm}$. And then, the position of the displacement controlled screw is adjusted in turn to make the dial indicator scale 1.22 $\mathrm{mm}, 1.83 \mathrm{~mm}$ and $2.44 \mathrm{~mm}$ respectively. The corresponding misalignment angle is $0.4^{\circ}, 0.6^{\circ}$, and $0.8^{\circ}$. Therefore, the meshing test can be carried out for both the conventional and novel crown gear couplings when misalignment angle is $0^{\circ}, 0.4^{\circ}, 0.6^{\circ}$, and $0.8^{\circ}$. The hub tooth in the pure pivoted area of the crown gear coupling in Fig. 12 is marked as tooth $\# 1$, and anticlockwise as tooth \#2, tooth \#3 until tooth \#40. 


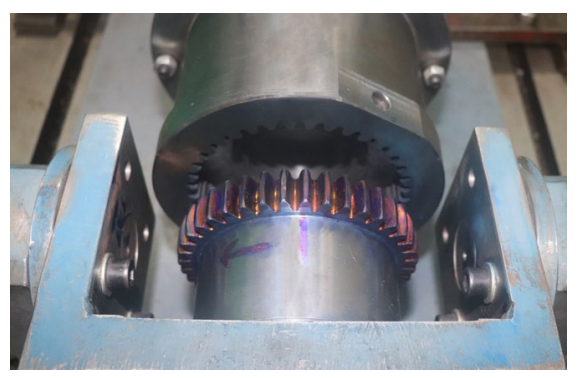

Fig. 12 Numbered hub tooth from \#1 to \#40 in a counter clockwise direction.

\subsection{Comparison of simulation and experimental results of the conventional crown gear coupling}

Fig. 13(a), Fig. 14(a), Fig. 14(b), Fig. 15(a), Fig. 15(b), Fig. 16(a) and Fig. 16(b) respectively show the meshing simulation result of the conventional crown gear coupling with misalignment angle $0^{\circ}, 0.4^{\circ}, 0.6^{\circ}$, and $0.8^{\circ}$. Fig. $13(\mathrm{~b})$, Fig. 14(c), Fig. 14(d), Fig. 15(c), Fig. 15(d), Fig. 16(c) and Fig. 16(d) respectively present the meshing experimental result of the conventional crown gear coupling with misalignment angle $0^{\circ}, 0.4^{\circ}, 0.6^{\circ}$, and $0.8^{\circ}$. And, figures (c) and (d) shown in Figs. 14, 15 and 16 are respectively the meshing experimental results of tooth \#13 and tooth \#33 having the minimum circumferential clearance between working tooth surfaces. In addition, Fig. 17 shows that the minimum circumferential clearance including the backlash between the working tooth surfaces of the conventional crown gear coupling changes with the tooth position when misalignment angle is $0^{\circ}, 0.4^{\circ}, 0.6^{\circ}$, and $0.8^{\circ}$. And, the minimum circumferential clearance in Fig. 17 is also obtained by the proposed tooth contact analysis (Guan et al., 2018) as the same as that shown in Fig. 5.

It can be seen from Fig. 13(a) and Fig. 13(b) that when misalignment angle is $0^{\circ}$, line contact on the hub tooth surface of the conventional crown gear coupling occurs in the middle plane of the hub tooth surface along the tooth width direction and every tooth is in contact whether according to the simulation results or the experimental results. This is because it can be seen from Fig. 17 that when misalignment angle is $0^{\circ}$, the minimum circumferential clearance between working tooth surfaces is always $0 \mu \mathrm{m}$. Thus, it can be seen that the simulation results of the conventional crown gear coupling are consistent with the experimental results when the hub is perfectly aligned with the sleeve.

(a)

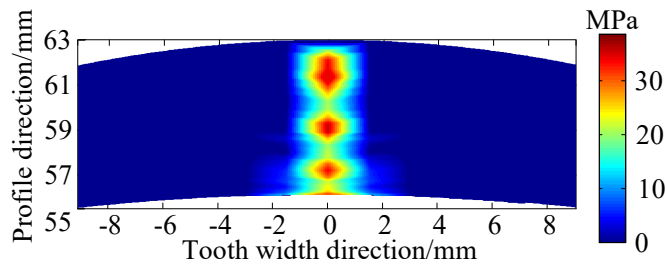

(b)

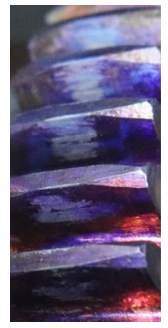

Fig. 13 Contact condition of the conventional crown gear coupling when misalignment angle is $0^{\circ}$ : (a) simulation result, and (b) experimental result.

(a)

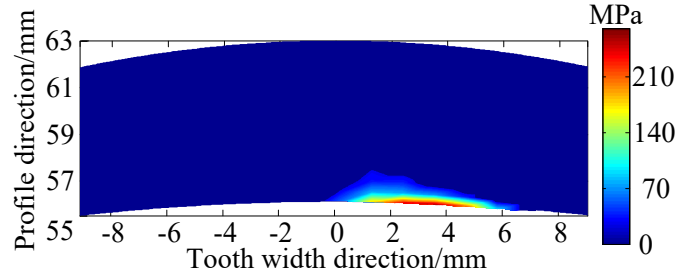

(c)

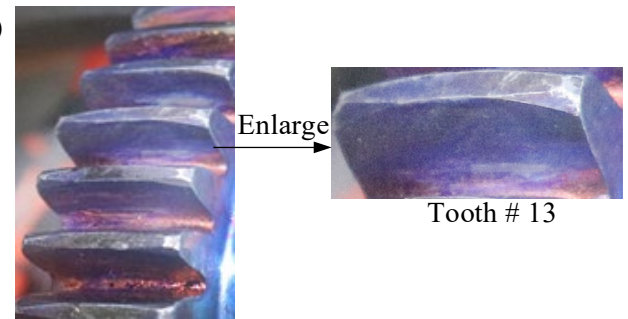

(b)

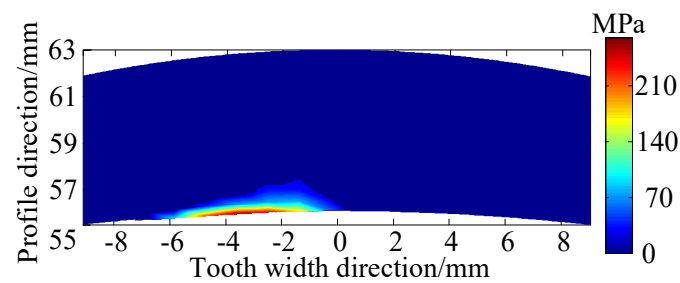

(d)

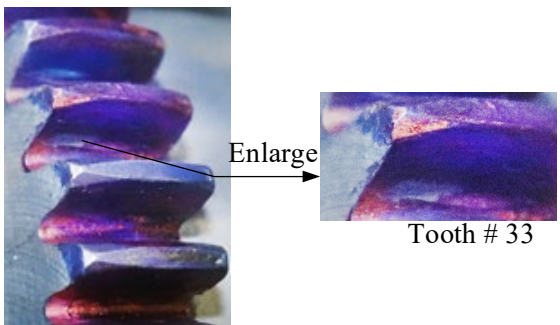

Fig. 14 Contact condition of the conventional crown gear coupling when misalignment angle is $0.4^{\circ}$ : (a) simulation result of tooth \#13, (b) simulation result of tooth \#33, (c) experimental result of tooth \#13, and (d) experimental result of tooth \#33. 
(a)

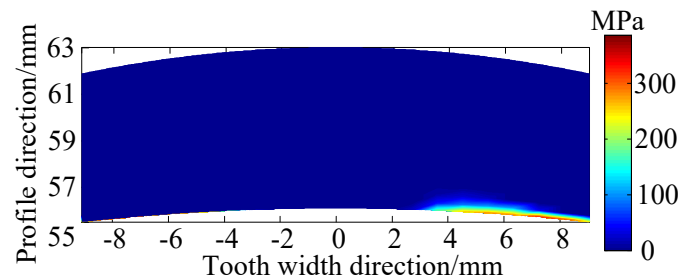

(c)

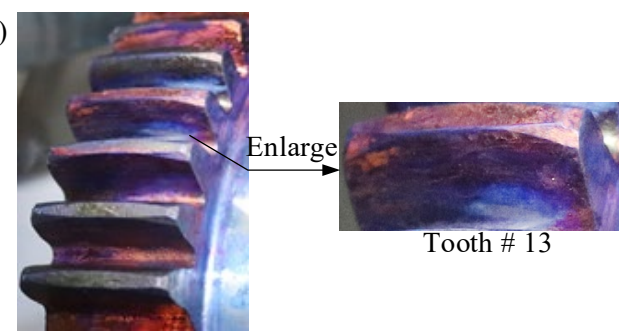

(b)

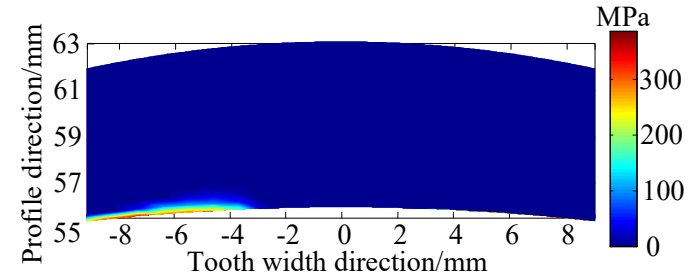

(d)

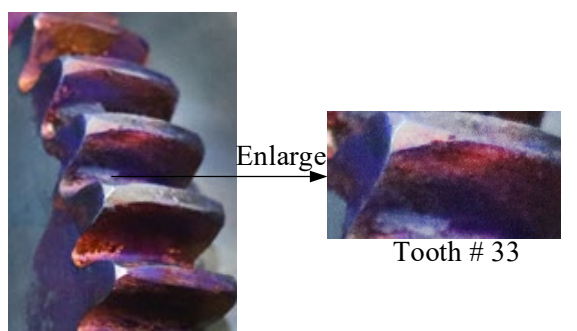

Fig. 15 Contact condition of the conventional crown gear coupling when misalignment angle is $0.6^{\circ}$ : (a) simulation result of tooth \#13, (b) simulation result of tooth \#33, (c) experimental result of tooth \#13, and (d) experimental result of tooth \#33.

(a)

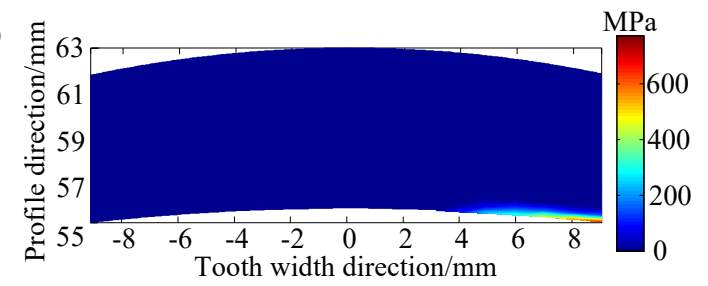

(c)

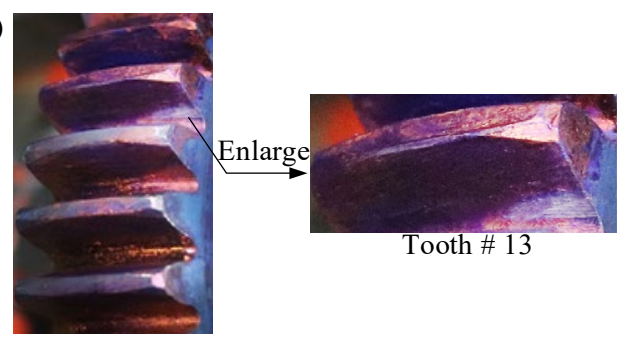

(b)

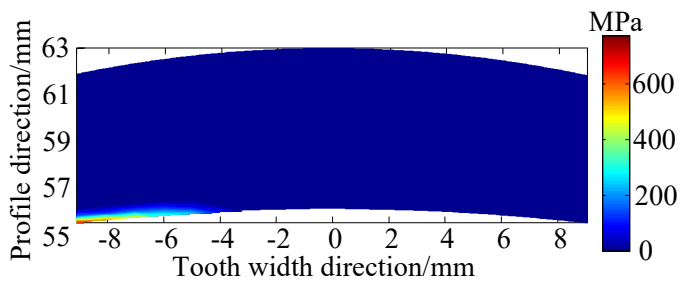

(d)

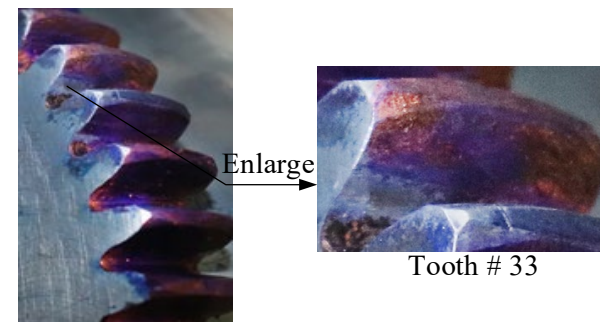

Fig. 16 Contact condition of the conventional crown gear coupling when misalignment angle is $0.8^{\circ}$ : (a) simulation result of tooth \#13, (b) simulation result of tooth \#33, (c) experimental result of tooth \#13, and (d) experimental result of tooth \#33.

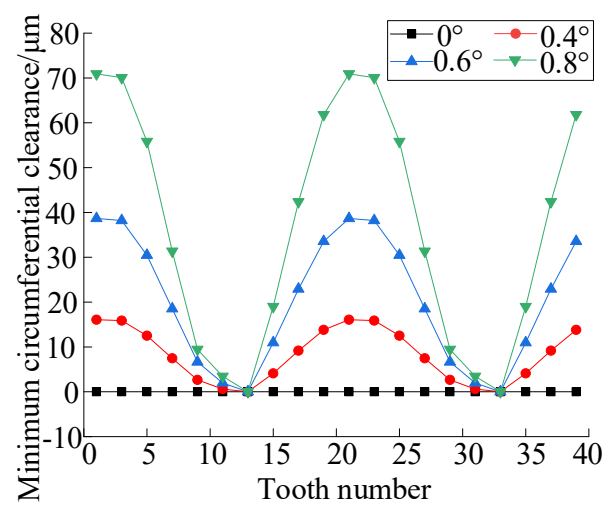

Fig. 17 Minimum circumferential clearance of the conventional crown gear coupling with four different misalignment angles changes with tooth number.

From Fig. 17, the minimum circumferential clearance between the working tooth surfaces of the conventional crown gear coupling at tooth \#13 and tooth \#33 (near the pure tilted area) is the minimum of all the tooth positions when misalignment angle is $0.4^{\circ}$. And, when the crown gear coupling is loaded, the teeth near the pure tilted area are the first to participate in contact. Besides, it can be also seen from Fig. 14(a) and Fig. 14(b) that contact positions of tooth \#13 and tooth \#33 are near the root of the hub tooth, and contact positions are on the side of midsection along the tooth width direction. These simulation results are consistent with the meshing experimental results shown in Fig. 14(c) and Fig. 14(d) separately when misalignment angle is $0.4^{\circ}$. The comparison of simulation and experimental results 
when misalignment angle is $0.6^{\circ}$ or $0.8^{\circ}$, can be referred to those above when misalignment angle is $0.4^{\circ}$. By comparing Fig. 15(a) and Fig. 15(b) with Fig. 15(c) and Fig. 15(d), and comparing Fig. 16(a) and Fig. 16(b) with Fig. 16(c) and Fig. 16(d), it can be concluded that the simulation results are consistent with the experimental results when misalignment angles are $0.6^{\circ}$ and $0.8^{\circ}$, respectively.

It can be seen from Fig. 14(c), Fig. 14(d), Fig. 15(c), Fig. 15(d), Fig. 16(c) and Fig. 16(d) that with the increase of misalignment angle, contact position on the hub tooth surface moves from the middle to the end along the tooth width direction. And, contact positions are always near the root of the hub tooth along the profile direction, which are consistent with the simulation results shown in Fig. 14(a), Fig. 14(b), Fig. 15(a), Fig. 15(b), Fig. 16(a) and Fig. 16(b).

\subsection{Comparison of simulation and experimental results of the novel crown gear coupling}

The effects of misalignment angle on contact characteristics obtained by simulation analysis and meshing experiment of the novel crown gear coupling are investigated. And, the simulation results are compared with the experimental results when misalignment angle is $0^{\circ}, 0.4^{\circ}, 0.6^{\circ}$, and $0.8^{\circ}$, respectively.

Fig. 18(a), Fig. 19(a), Fig. 19(b), Fig. 20(a), Fig. 20(b), Fig. 21(a) and Fig. 21(b) respectively show the meshing simulation result of the novel crown gear coupling with misalignment angle $0^{\circ}, 0.4^{\circ}, 0.6^{\circ}$, and $0.8^{\circ}$. Fig. $18(\mathrm{~b})$, Fig. 19(c), Fig. 19(d), Fig. 20(c), Fig. 20(d), Fig. 21(c) and Fig. 21(d) respectively present the meshing experimental result of the novel crown gear coupling with misalignment angle $0^{\circ}, 0.4^{\circ}, 0.6^{\circ}$, and $0.8^{\circ}$. And, figures (c) and (d) shown in Figs. 19, 20 and 21 are respectively the meshing experimental results of tooth \#13 and tooth \#33 having the minimum circumferential clearance between working tooth surfaces. In addition, Fig. 22 shows that the minimum circumferential clearance including the backlash between the working tooth surfaces of the novel crown gear coupling changes with the tooth position when misalignment angle is $0^{\circ}, 0.4^{\circ}, 0.6^{\circ}$, and $0.8^{\circ}$. And, the above minimum circumferential clearance is also obtained by the proposed tooth contact analysis (Guan et al., 2018).

From Fig. 18(a) and Fig. 18(b), it can be observed that when misalignment angle is $0^{\circ}$, point contact on the hub tooth surface of the novel crown gear coupling occurs in the middle both along the tooth width direction and along the profile direction. Moreover, every tooth is in contact because the minimum circumferential clearance between working tooth surfaces is always $0 \mu \mathrm{m}$ when misalignment angle is $0^{\circ}$, which can be obtained from Fig. 22. Therefore, the simulation results of the novel crown gear coupling are consistent with the experimental results when the hub is perfectly aligned with the sleeve.

(a)

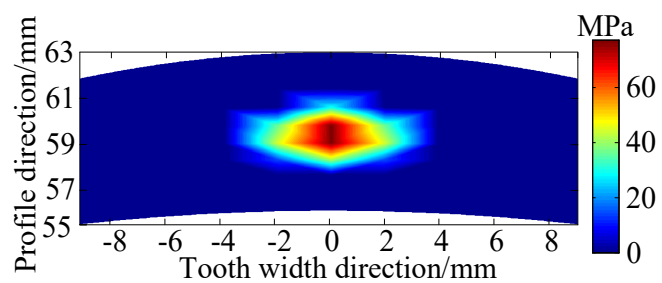

(b)

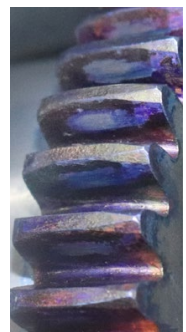

Fig. 18 Contact condition of the novel crown gear coupling when misalignment angle is $0^{\circ}$ : (a) simulation result, and (b) experimental result.

(a)

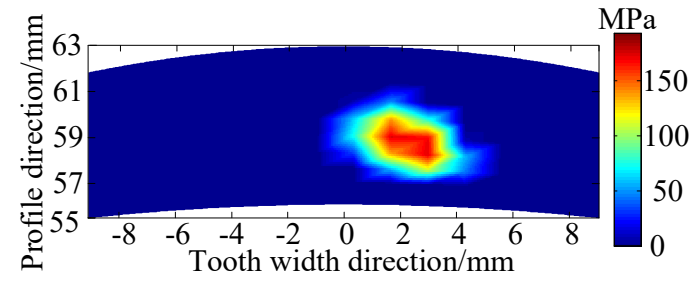

(c)

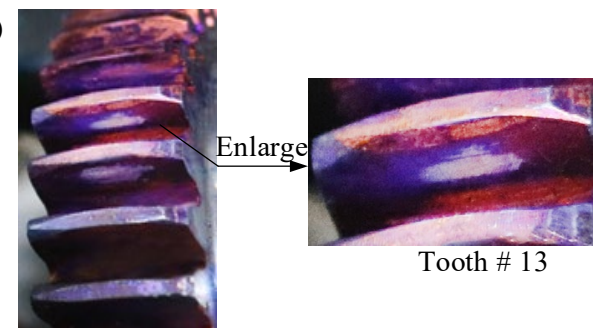

(b)

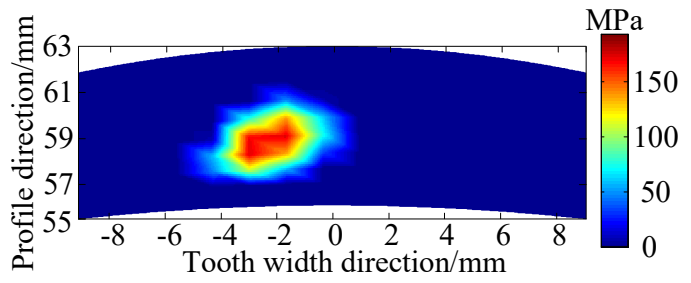

(d)

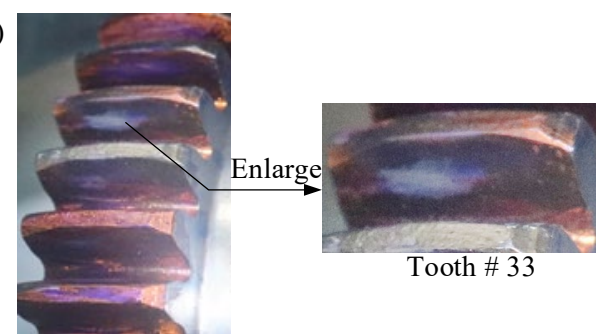

Fig. 19 Contact condition of the novel crown gear coupling when misalignment angle is $0.4^{\circ}$ : (a) simulation result of tooth $\# 13$, (b) simulation result of tooth \#33, (c) experimental result of tooth \#13, and (d) experimental result of tooth \#33. 
(a)

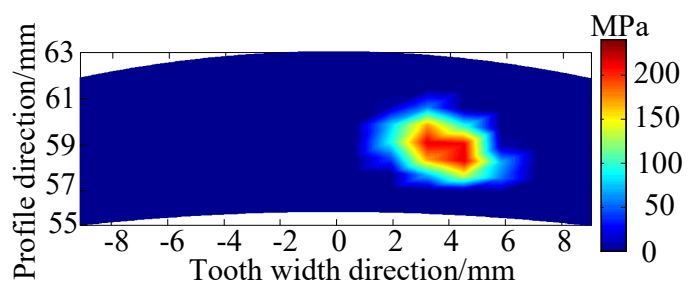

(c)

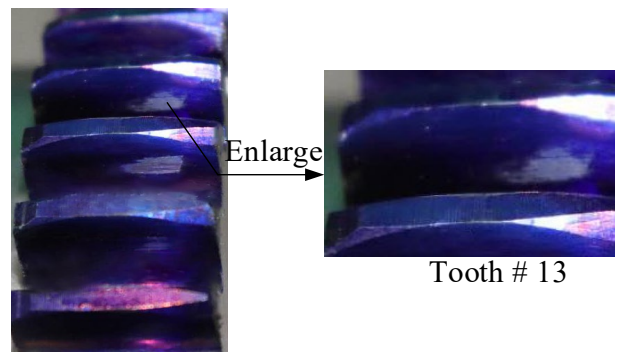

(b)

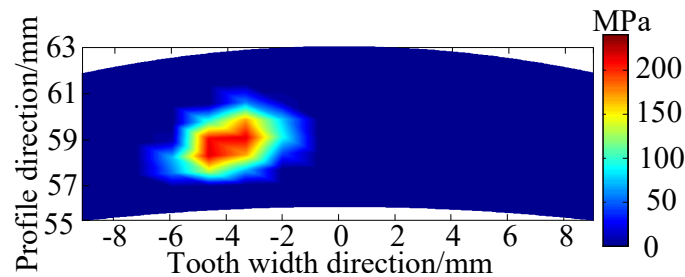

(d)

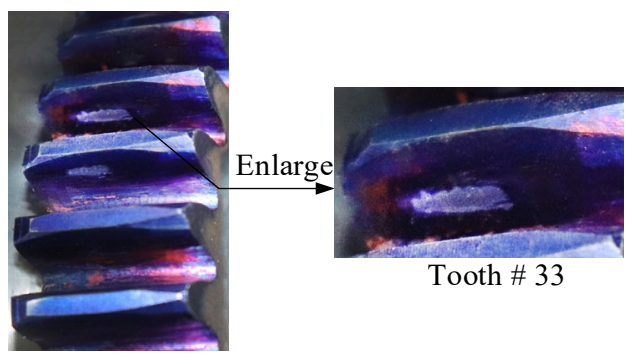

Fig. 20 Contact condition of the novel crown gear coupling when misalignment angle is $0.6^{\circ}$ : (a) simulation result of tooth $\# 13$, (b) simulation result of tooth \#33, (c) experimental result of tooth \#13, and (d) experimental result of tooth \#33.

(a)

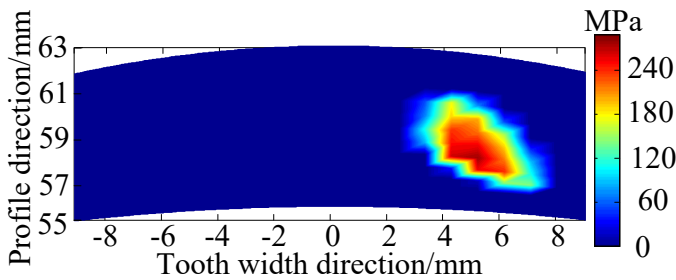

(c)

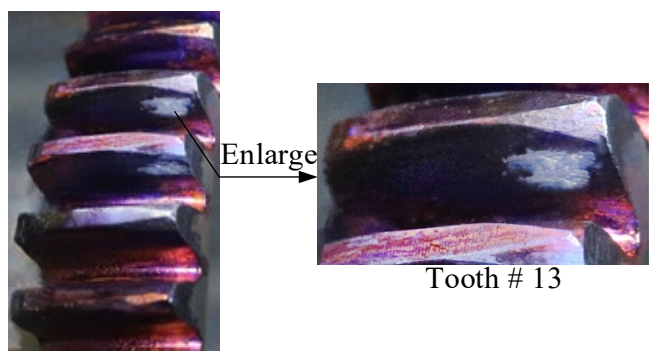

(b)

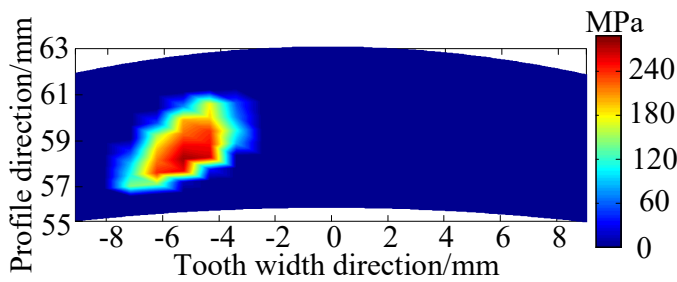

(d)

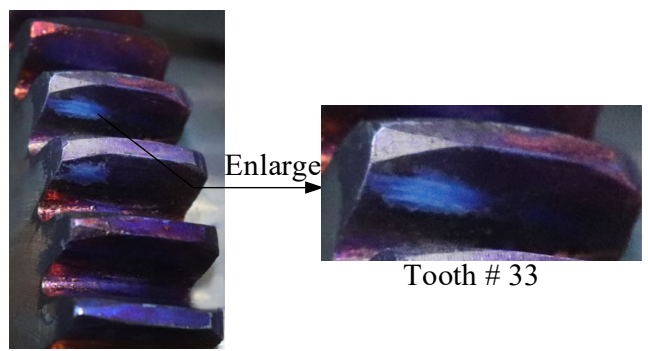

Fig. 21 Contact condition of the novel crown gear coupling when misalignment angle is $0.8^{\circ}$ : (a) simulation result of tooth $\# 13$, (b) simulation result of tooth \#33, (c) experimental result of tooth \#13, and (d) experimental result of tooth \#33.

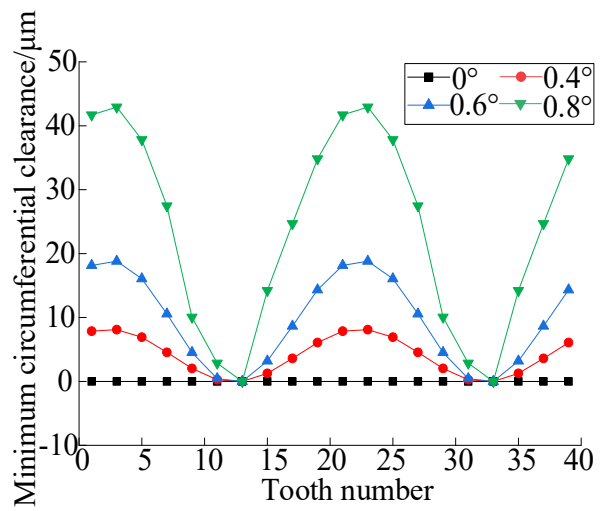

Fig. 22 Minimum circumferential clearance of the novel crown gear coupling with four different misalignment angles changes with tooth number.

As seen from Fig. 22, the minimum circumferential clearance between the working tooth surfaces of the novel crown gear coupling at tooth \#13 and tooth \#33 (near the pure tilted area) is the minimum of all the tooth positions when misalignment angle is $0.4^{\circ}$. And, when the crown gear coupling is loaded, the teeth near the pure tilted area are the first to participate in contact. Besides, it can be also seen from Fig. 19(a) and Fig. 19(b) that contact positions of tooth \#13 and tooth \#33 are located at the middle of the hub tooth surface along the profile direction. These simulation 
results agree with the experimental results shown in Fig. 19(c) and Fig. 19(d) separately when misalignment angle is $0.4^{\circ}$. The comparison of simulation and experimental results when misalignment angle is $0.6^{\circ}$ or $0.8^{\circ}$, can be referred to those above when misalignment angle is $0.4^{\circ}$. By comparing Fig. 20(a) and Fig. 20(b) with Fig. 20(c) and Fig. 20(d), and comparing Fig. 21(a) and Fig. 21(b) with Fig. 21(c) and Fig. 21(d), it can be obtained that the simulation results are consistent with the experimental results when misalignment angle is $0.6^{\circ}$ and $0.8^{\circ}$.

In addition, it can be also observed from Fig. 19(c), Fig. 19(d), Fig. 20(c), Fig. 20(d), Fig. 21(c) and Fig. 21(d) that with the increase of misalignment angle, contact position on the hub tooth surface moves from the middle to the end along the tooth width direction. And, contact positions are always in the middle of the hub tooth along the profile direction, which are consistent with the simulation results shown in Fig. 19(a), Fig. 19(b), Fig. 20(a), Fig. 20(b), Fig. 21(a) and Fig. 21(b).

\subsection{Comparison of experimental results between the conventional and novel crown gear couplings}

Fig. 23(a) and Fig. 23(b) show the experimental results of the conventional and novel crown gear couplings respectively when misalignment angle is $0.8^{\circ}$ which is the maximum.
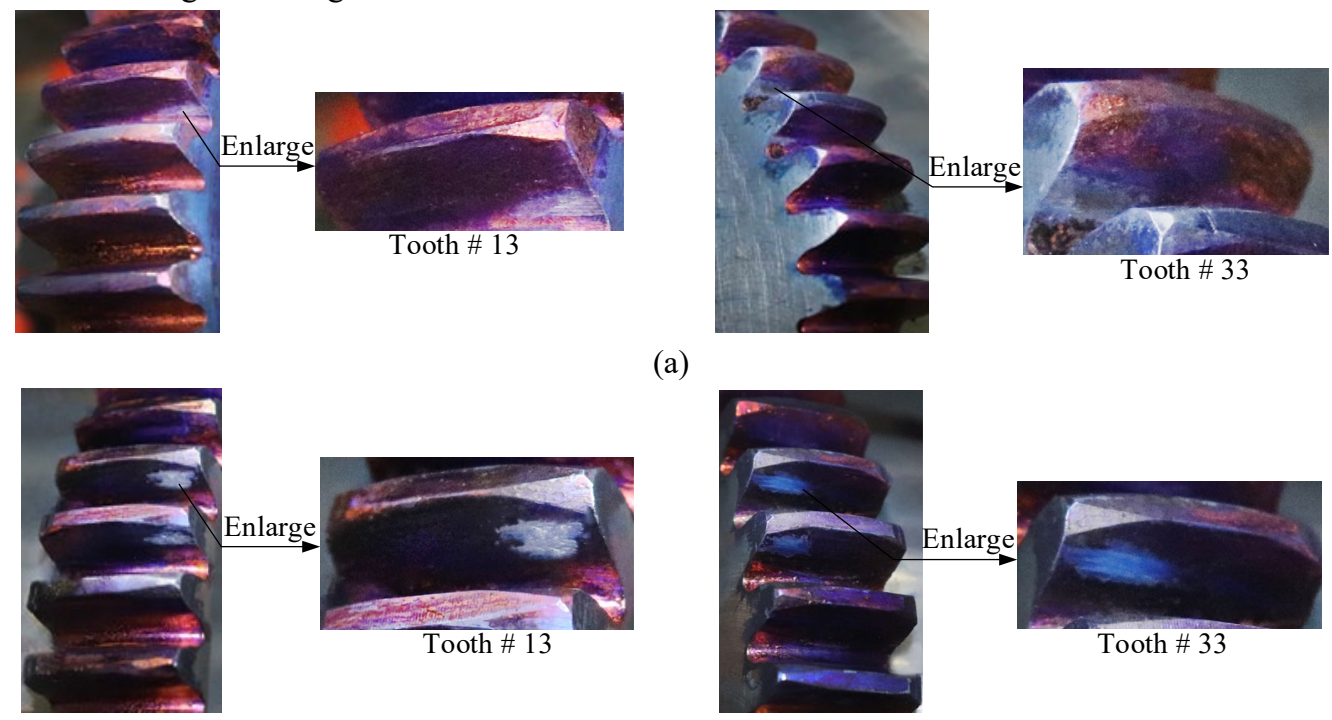

(b)

Fig. 23 Comparison of experimental results between the conventional and novel crown gear couplings when misalignment angle is $0.8^{\circ}$ : (a) contact condition of teeth \#13 and \#33 of the conventional crown gear coupling, and (b) contact condition of teeth \#13 and \#33 of the novel crown gear coupling.

Comparing Fig. 23(a) and Fig. 23(b), it can be found that when misalignment angle is $0.8^{\circ}$, contact positions of tooth \#13 and tooth \#33 of the novel crown gear coupling are located in the middle along the profile direction, which indicates that the innovative hub tooth profile can effectively avoid the occurrence of the hub tooth tip edge contact with the sleeve tooth root flank and the sleeve tooth tip edge contact with the hub tooth root flank. In addition, it can be seen that there is no obvious edge contact along the tooth width direction of the novel crown gear coupling, which denotes that the innovative hub tooth profile can also reduce the sensitivity of meshing contact to misalignment angle.

\section{Conclusion}

In this study, a dedicated test rig which can adjust misalignment angle of crown gear coupling to measure the meshing performance was designed and set up. According to conventional tooth modification theory and innovative tooth modification theory for the hub, the specimens for test were designed and processed, and the machining accuracy of tooth surface was tested. On the test rig, the engagement tests for the conventional and novel crown gear couplings with different misalignment angles were conducted. In addition, simulation results obtained by loaded tooth contact analysis for the conventional and novel crown gear couplings have been compared to the experimental results separately. The results of this study lead to the following conclusions:

- For both the conventional and novel crown gear couplings, the larger misalignment angle applied to the crown gear coupling, the farther the contact position away from the middle of the face width of the crown gear coupling. 
- For the conventional crown gear coupling, contact positions are always at locations near the root of the hub tooth surface when the hub is misaligned with the sleeve.

- Compared with the conventional crown gear coupling, the innovative hub tooth profile of the novel crown gear coupling can effectively avoid the occurrence of the edge contact along the profile direction and reduce the sensitivity of meshing contact to misalignment angle.

- The simulation results obtained by loaded tooth contact analysis agrees well with the experimental results as it accurately captures the variation of contact positions with the variation of misalignment angle.

\section{References}

Alfares, M. A., Falah, A. H. and Elkholy, A. H., Clearance distribution of misaligned gear coupling teeth considering crowning and geometry variations, Mechanism and Machine Theory, Vol.41, No.10 (2006), pp. 1258-1272.

Fan, W., Lu, H., Zhang, Y. Q., and Su, X. G., Dynamic characteristics of gear coupling and rotor system in transmission process considering misalignment and tooth contact analysis, Processes, Vol.8, No.11 (2020), pp. 1-23.

Guan, Y. B., Fang, Z. D., Yang, X. H. and Chen, G. D., Tooth contact analysis of crown gear coupling with misalignment, Mechanism and Machine Theory, Vol.126, No.8 (2018), pp. 295-311.

Guan, Y. B., Yang, X. H., Fang, Z. D. and Chen, G. D., Comparative analysis of three geometric models for crown gear coupling, Mechanism and Machine Theory, Vol.136, No.6 (2019a), pp. 269-283.

Guan, Y. B., Yang, X. H., and Fang, Z. D., Computerized generation and simulation of meshing of a novel crown gear coupling avoiding edge contact, Journal of Advanced Mechanical Design, Systems, and Manufacturing, Vol.13, No.3 (2019b), DOI: 10.1299/jamdsm.2019jamdsm0055.

Guo, Y., Keller, J., Errichello, R. and Halse, C., Gearbox reliability collaborative analytic formulation for the evaluation of spline couplings, National Renewable Energy Laboratory Technical Report (2013), Paper No. NREL/TP-5000-60637.

Guo, Y., Keller, J., Wallen, R., Errichello, R., Halse, C. and Lambert, S., Design evaluation of wind turbine spline couplings using an analytical model, National Renewable Energy Laboratory Technical Report (2015), Paper No. NREL/CP-5000-63507.

Guo, Y., Lambert, S., Wallen, R., Errichello, R. and Keller, J., Simulation and experimental study on gear-coupling contact and loads considering misalignment, torque, and friction influences, Mechanism and Machine Theory, Vol.98, No.4 (2016), pp. 242-262.

Hakozaki, Y. and Shimachi, S., Equalization about the tooth bearing area for the shaft angle of gear coupling, Transactions of the Japan Society of Mechanical Engineers, Series C, Vol.73, No.2 (2004), pp. 594-601 (in Japanese).

He, Y. Y., The studies on the key technology of crown coupling and its application (2013) (in Chinese), pp. 52-59, Henan University of Technology.

Keum, B., Analysis of 3-D contact mechanics problems by the finite element and boundary element methods (2003), pp. 29-40, University of Cincinnati.

Locke, S. R., Burgess, M. J. and Corcoran, J. P., Coupling credible failure modes and owner options to intervene, Proceedings of the 42nd turbomachinery symposiums (2013), pp. 1-30.

Ohshima, F., Hirata, S., and Yoshino, H., Study on tooth contact of gear couplings, Transactions of the Japan Society of Mechanical Engineers, Series C, Vol.78, No.786 (2012), pp. 639-649 (in Japanese).

Peng, Y., Sun, J. L., Zhang, Y. and Zhang, M., Dynamic model system for stable operation of strip mill and its industrial application (2018) (in Chinese), pp. 143-170, China Machine Press.

Shinoda, M., and Li, S. T., Study on teeth contact pattern and strength analysis of gear couplings used in railway vehicles, The Proceedings of Conference of Chugoku-Shikoku Branch (2020), pp. 04c2.

Wang, D. D., and Shen, W. B., Test of crown gear coupling, Locomotive and Rolling Stock Technology, Vol.43, No.1 (2006), pp. 35-37 (in Chinese).

Zhao, S. Y., Yao, Y. Zhao, and Li. Y. M., Optimization and contrast analysis of different crown profile for crown gear coupling, Journal of Mechanical Transmission, Vol.41, No.10 (2017), pp. 86-91 (in Chinese). 